\title{
Doing business in China and performance: A review of evidence
}

\author{
(Diego Quer, Enrique Claver and Laura Rienda)
}

\begin{abstract}
Purpose The number of papers focusing on foreign companies doing business in China has increased significantly since the open-door policy came into effect in the late 1970s. Performance has been one of the most researched topics. Our aim is to carry out a review of the empirical papers which have analysed the performance drivers of foreign companies in mainland China.

Design/methodology/approach This study reviews 62 empirical papers dealing with the performance of foreign firms in mainland China, published in 10 leading international academic journals between 1978 and 2006.

Findings An analysis of the main findings is offered, along with a summary of the theoretical approaches, methodologies, samples and performance measures used.

Originality/value This paper identifies the factors which contribute to greater performance in mainland China. Although other studies have reviewed the literature in the Chinese context, none had specifically tackled this topic through a comprehensive review.
\end{abstract}

Keywords Mainland China, foreign companies, performance drivers.

Paper type Literature review. 


\section{Introduction}

Since the open-door policy came into effect in the late 1970s, China's economic structures have undergone a deep transformation, one of the most relevant consequences of which being China's entry into the World Trade Organisation (WTO) in 2001. Attracting foreign capital has been one of the prime objectives throughout this period and the main reason the Chinese authorities decided to liberalise foreign investments progressively in an attempt to create a suitable, favourable setting.

The results have been amazing, as shown by the increased foreign direct investment (FDI) flows received by the country, where the US\$ 57 million received in 1980 jumped to US\$ 3,487 million in 1990 and reached an impressive US\$ 40,715 million in 2000. With the record figure of US\$ 83,521 million achieved in 2007, China remained the top destination among developing economies for inward FDI (UNCTAD 2008). This financial and technological injection from abroad has undoubtedly played an essential role in the economic development of China, which has been growing at rates above $10 \%$ over the past few years.

Although in recent years foreign firms have invested substantially in China, they continue to encounter serious strategic challenges from the unprecedented and rapid changes in this market (Li, Zhou, and Shao 2009). Managers of foreign companies are all trying to learn about how to be successful in China since they know that they must outperform in China in order to compete globally. For this reason, performance of foreign firms has been one of the most researched topics in the literature focusing on business and management in the Chinese context.

Previous literature reviews have dealt with business and management research in China (Li and Tsui 2002; Nippa, Beechler, and Klossek 2007; Peng, Lu, Shenkar, and Wang 2001; Quer, Claver, and Rienda 2007; Roy, Walters, and Luk 2001; Shenkar 1994; Shenkar and Von 
Glinow 1994; Tsui, Schoonhoven, Meyer, Lau and, Milkovich 2004; Zhou and Li 2007). However, only the review of Nippa et al. (2007) dealt with the performance determinants of foreign companies doing business in China. They compared success factors between Sinoforeign joint ventures and international joint ventures (IJVs) located in other countries. Nevertheless, their review covered the 1991-2005 period, including only 16 empirical papers on Sino-foreign joint ventures based on quantitative data, thus excluding papers focused on other entry modes in China as well as qualitative research ${ }^{1}$.

Therefore, our aim is to carry out a wider review of the empirical papers which have analysed the performance drivers of foreign companies in mainland China since the open-door policy came into effect (1978 to 2006, inclusive). More precisely, we attempt to answer the following question: how far do factors such as relationships with local partners, cultural differences, managerial networks, previous experience, entry timing, entry mode, human resource management practices, or industry structure matter? In addition, we offer a summary of the theoretical approaches, methodologies, samples and performance measures used in the papers.

\section{Methodology and descriptive analysis}

\subsection{Journal and paper selection}

We considered 10 outstanding, high-impact international journals, organised into three groups. These 10 include five top journals dealing specifically with international business and management (Journal of International Business Studies, [Columbia] Journal of World Business, International Business Review, Management International Review, and Journal of International Management), four top management journals (Academy of Management Journal, Journal of 
Management Studies, Organization Science, and Strategic Management Journal) and the leading journal in the field of Asian management (Asia Pacific Journal of Management).

This journal selection is supported by various journal rankings (Acedo and Casillas 2005; Dubois and Reeb 2000), previous reviews of the international business and management literature (Chan, Fung, and Leung 2006; Kumar and Kundu 2004; Lohrke and Bruton 1997; Lu 2003; Morrison and Inkpen 1991; Peng and Zhou 2006; Werner 2002; Werner and Brouthers 2002; Xu, Yalcinkaya, and Seggie 2008; Yang, Wang, and Su 2006) and earlier literature reviews on doing business in China (Li and Tsui 2002; Nippa et al. 2007; Peng et al. 2001; Quer et al. 2007; Tsui et al. 2004).

After identifying the journals to be analysed, the next step was to select the papers to be reviewed. The period analysed was between 1978 and 2006 (inclusive). We only considered papers with an empirical content focusing on mainland China. Therefore, conceptual papers and empirical papers including samples from Hong Kong, Taiwan or Macao were left out. After reviewing their objectives and methodologies, we identified 189 papers dealing with foreign companies doing business in mainland China. Sixty-two of these analysed issues relating to the performance of foreign companies. Thus, this is the sample that will be the subject of our review.

\subsection{Contributions per journal}

Overall, the 62 papers were distributed as follows: 1 (in 1980-1989), 21 (in 1990-1999), and 40 (in 2000-2006). A distribution of the papers according to the journals in which they were published is provided in Table 1. 
Table 1 List of journals analysed (1978-2006)

\begin{tabular}{lc}
\hline \multicolumn{1}{c}{ Journal } & $\begin{array}{c}\text { Empirical papers on performance of foreign } \\
\text { companies in mainland China (1978-2006) }\end{array}$ \\
\hline 1. Journal of International Business Studies (JIBS) & 13 \\
2. Asia Pacific Journal of Management (APJM) & 9 \\
2. International Business Review (IBR) & 9 \\
4. Management International Review (MIR) & 8 \\
5. Journal of Management Studies (JMS) & 6 \\
6. Journal of International Management (JIM) & 5 \\
7. Journal of World Business (JWB) & 4 \\
7. Strategic Management Journal (SMJ) & 4 \\
9. Academy of Management Journal (AMJ) & 3 \\
10. Organization Science (OS) & 1 \\
\multicolumn{2}{c}{ Total } \\
\hline \hline
\end{tabular}

${ }^{a}$ Until 1996, known as The Columbia Journal of World Business (CJWB)

The journal which published the highest number of empirical papers on the performance of foreign companies in mainland China between 1978 and 2006 is JIBS, with 13 papers (21\% of the total of 62 papers). APJM and $I B R$ rank second with 9 papers $(14.5 \%)$ each, followed by $M I R$ with $8(12.9 \%)$. These four journals $(J I B S, A P J M, I B R$, and $M I R)$ account for 39 of the 62 papers identified or, more precisely, $62.9 \%$.

\subsection{Methodology, sample and performance measures used in the papers}

With regard to the research methodology used, there is a clear prevalence of quantitative studies based on surveys (45 papers, $72.6 \%$ ). These are followed by qualitative studies, based on case studies or in-depth interviews (13 papers, 20.9\%), with quantitative studies based on secondary data bringing up the rear (4 papers, $6.5 \%)$.

The samples analysed mostly come from several countries, their origin not being specified (43 papers, 69.4\%). Among papers studying foreign companies from a single country, there was a prevalence of those which had concentrated on companies from the US (6 papers) and Japan (3 papers). Subjective performance measures are favoured over objective measures (33 papers, 53.2\%, compared to 23 papers, 37.1\%). The remaining studies (6 papers, 9.7\%) 
either combined both types of measure, used presence on a list of profitable projects as a guide or used no specific measure, their aim being to identify performance criteria.

\section{Performance of foreign firms in mainland China: Main findings}

In this section, we report the main findings of the 62 papers included in our review. With the aim of comparing the findings and providing the reader with a systematic overview, papers have been grouped into several categories, each category covering papers dealing with similar topics. In this case, any classification attempt becomes complicated when one sees the wide range of topics and perspectives included in the papers. The categories were created post hoc, based on a thorough reading of the 62 papers. Because no formal content coding method was used, these categories should be treated as an organizing tool rather than a definitive classification. Thus, the order of the following subheadings does not imply any priority.

\subsection{Managing inter-partner relationships in IJVs}

Transaction cost economics, agency theory and contingency theory have been the mainstream theoretical perspectives used in papers dealing with inter-partner relationships. Luo and Park (2004) verified that cooperation between partners affected performance positively and that greater market uncertainty requires greater cooperation between all parties: the local partner, the foreign partner and the managers of the IJV.

Several empirical findings underline the importance and direction of this cooperation: the performance of the IJV will be greater the better the compatibility between partners on strategic objectives, the contribution and joint management of critical resources, and the consensus on culture, strategy and policies (Yan and Duan 2003); the quality of the interpartner working relationship (consensus on strategy and operating procedures) has a strong, positive relationship 
with the achievement of strategic objectives for both partners (Yan and Gray 2001); the personal attachments between the boundary spanners of each party and the structural attachments between partners at an organisational level (e.g. cooperation and joint decision making) contribute positively to performance, albeit at a decreasing rate as these attachments increase (Luo 2002c); the IJV is more profitable when the boundary spanners of both parties perceive a high level of procedural justice, than in situations when only one of the parties perceives it (Luo 2005).

Finally, two conflict resolution strategies influence perceived performance differently (Lin and Germain 1998): the problem-solving strategy (discussing openly concerns, priorities, ideas, and issues, and searching for solutions that satisfy both parties' needs) affects performance positively, while the legalistic strategy (resorting to written contracts and informal binding agreements to obtain the desired outcome to a conflict), has a negative effect on performance ${ }^{2}$.

This empirical evidence leads us to establish the following proposition:

Proposition 1: Cooperation between partners (in making decisions, establishing objectives or solving conflicts) is positively associated with the performance of IJVs in China.

\subsection{Management control and autonomy of IJVs}

Papers in this category have taken different perspectives such as organizational learning, control structure or bargaining power theory. Yan and Duan (2003) observed that IJVs performed better when there was a better fit between the relative bargaining power of each partner and their level of management control over the IJV.

The power to appoint managers is the control mechanism that obtained the greatest empirical support as a performance driver: foreign partners with the power to appoint personnel to key positions perceive that they have greater control over the IJV and are more satisfied with 
the performance (Wang, Wee, and Koh 1998, 1999); the level of operational control exercised by a partner over the IJV (appointing senior executives and establishing their decision power) has a positive effect on the extent to which this partner's strategic objectives are achieved (Yan and Gray 2001); a greater degree of overall control (general influence on activities and percentage of members on the board of directors) and specific control (influence in specific areas) in the IJV is associated with greater performance perceived by the foreign partner (Luo, Shenkar, and Nyaw 2001).

The level of control held through ownership of the IJV has also been researched, with the finding that a majority equity share improves performance as perceived by the foreign partner (Lin and Germain 1998; Luo, Shenkar, and Nyaw 2001).

Nevertheless, according to findings from other studies, empirical evidence on the positive influence of foreign control is not totally conclusive. Thus, Yan and Gray (1994) find that when the structure of management control distribution in the IJV is balanced, the performance of each partner is also balanced (both achieve their most important strategic objectives); while when control is distributed unequally, the performance forecast is less straightforward (sometimes performance is balanced; other times the partner holding greater control obtains greater performance). Moreover, the degree of trust between partners, the existence of common strategic objectives and the institutionalisation of goals moderate the relationship between parent control and performance.

Child and Yan (2003) find that sharing control with local partners affects performance positively, although only when the resources provided by the foreign partner are of high quality. Other studies even point to the advantages of giving autonomy to the IJV. Thus, Zhang and Li (2001) verified that greater independence in the IJV is associated with higher performance and 
that the search for greater performance stimulates the evolution of the control system as follows: 1) shared control, 2) dominant partner, 3) independence. Similarly, Newburry, Zeira and Yeheskel (2003) reported that the effectiveness of the IJV was higher the more autonomy it had to implement, though not to formulate, strategic business plans.

In short, in view of the diversity of the findings obtained regarding the influence of control structure on performance, we make the following proposition:

Proposition 2: Greater control over the IJV by the foreign partner does not necessarily lead to improved performance in China.

\subsection{IJV contracts}

Transaction cost economics and contingency theory have been the main theoretical frameworks used to analyse the influence of IJV contracts on performance. During the contract negotiation phase, specification in the main terms, clauses and conditions of the transactions and the inclusion of relevant issues are positively related with the performance of the IJV (Luo and Shenkar 2002). Moreover, the more complete contracts are, the more the cooperation between the partners contributes to performance (Luo 2002a). At the same time, the alignment between contractual design and environmental conditions has positive effects on performance, in accordance with the following relationships (Luo and Tan 2003): contingency coverage (in the contract) with dynamism, complexity and hostility (in the environment); inclusion of many issues (in the contract) with dynamism (in the environment).

In the contract implementation phase, Yan and Child (2004) observed that greater investment in contractual resources by the foreign partner (resources provided to the IJV on the basis of formal contracts or written agreements) led to greater satisfaction with performance. 
However, this is not true for non-contractual resources (resources provided beyond any formal contract or written agreement).

Finally, contract protection to mitigate the liabilities of foreignness in China has different implications on performance, according to the approach used (Luo, Shenkar, and Nyaw 2002): although it reduces production and marketing costs, it does not stimulate growth in sales revenues.

This leads us to the following propositions:

Proposition 3a: An appropriate contractual design, adapted to environmental conditions in China, has a positive impact on performance.

Proposition 3b: Investment in contractual resources by the foreign partner improves performance in China; this is not true for investment in non-contractual resources.

Proposition 3c: Contract protection has different implications on performance in accordance with the measure used.

\subsection{Cultural differences in IJVs}

Cultural distance has to do with the possible differences existing in relation to the way individuals from different countries observe certain behaviours, which will influence the validity of the transfer of work practices and methods from one country to another (Hofstede 1980).

Drawing on transaction cost economics, resource dependence theory and the resourcebased view, some papers analysed the influence of cultural differences on the performance of IJVs in China. However, empirical evidence is not entirely conclusive. While Lin and Germain (1998) found that cultural similarity between partners is positively related with performance satisfaction, Li, Karakowsky and Lam (2002) could not confirm that a smaller cultural distance between partners positively affects performance. Li, Lam and Qian (2001) even report that IJVs 
with a Western foreign partner (i.e. from a more individualistic culture) outperform those established in China by Asian countries ${ }^{3}$.

With regard to the heterogeneity of cultural values in the IJV management team, Li et al. (2002) showed that an appropriate management team diversity in culture leads to the best firm performance, i.e. neither too low nor too high cultural diversity is beneficial for performance.

In view of these findings, we make the following proposition:

Proposition 4: A smaller cultural distance between partners may be positively related with IJV performance or may have no direct effect on it.

\subsection{Guanxi: A strong cultural parameter in the Chinese context}

Closely related to Chinese culture is guanxi. The Chinese word guanxi primarily relates to personal relations and involves the exchange of social obligations or favours (renqing) and the giving of social status or face in the society (mianzi). It is widely recognised that guanxi is a key practically significant business determinant influencing firm performance because the lifeblood of the Chinese economy and business conduct is guanxi network (Luo and Chen 1996). Guanxi can enhance a firm's competitive advantage by providing access to the resources of other network members (suppliers, buyers or distributors), and is particularly important regarding entry into the market. Its roots are deeply embedded in the Chinese culture for more than 2,000 years. Ever since Confucius codified the societal rules and values, the Chinese society has been functioning as clan-like networks. Such networks can be viewed as concentric circles, with close family members as the core and distant relatives, classmates, friends, and acquaintances as peripherals arranged in accordance to the distances of relationships and degrees of trust.

Institutional theory and managerial networking have been the main theoretical approaches used in the study of the link between guanxi and performance. Grow (1986) observed that the 
most important factor for success in selling products or services in China was the foreign company's commitment to build close relationships with the Chinese managers responsible in their companies for deciding to buy foreign products and technologies. Similarly, Abramson and Ai (1999) found that foreign companies that established guanxi relationships (based on trust and shared goals) obtained higher performance than those using transactional relationships.

Most studies on this issue have also observed a positive association between guanxi and performance, although using different variables and measures. Thus, Luo et al. (2002) observed that guanxi enhances sales revenues, but does not reduce production and marketing costs, while Luo (1995) found that profitability and domestic sales growth improve thanks to two variables linked to guanxi: the intensity of sales force expenditure (because a sales person can use his/her network of social relationships in China to promote the products) and the intensity of the accounts receivable for the seller (as a reflection of credit facilities granted).

The influence of these two guanxi-related variables has been observed in other studies (Luo 1997a; Luo and Chen 1996, 1997): the intensity of the sales force expenditure has a positive effect on domestic sales growth, asset turnover (total sales revenue/total assets) and return on investment (ROI); the intensity of the accounts receivable for the seller has a positive effect on domestic sales growth; while the intensity of the accounts payable by the buyer (the other side of credit-granting) has a positive effect on asset turnover. Moreover, the positive effects on performance of these three guanxi-related variables are greater in IJVs than in whollyowned subsidiaries (WOSs), when the foreign company comes from a country that is culturally close to China and the longer they have been operating in China.

With regard to relationships between the foreign company and government officials, Li (2005) observed that its impact on performance is weaker than the impact of ties with other 
business community managers. However, relationships with the Chinese government act as a communication facilitator (Sanyal and Guvenli 2000): good communication with the government and the freedom to set product prices without government interference are significantly correlated with the realization of the strategic goals of the subsidiary; developing close links with the government improves communication and makes it easier to obtain its support in order to solve problems in the subsidiary, which, in turn, favours the full use of its productive capacity; however, no significant relationship was observed between links with the government and profitability.

In any case, the implications for performance are different depending on the regional or national level of the government authority (Luo 2001): stronger relations with the government at national level promote greater sales growth and asset turnover; close relationships with regional government also favour ROI.

This empirical evidence on the influence of guanxi leads us to formulate the following propositions:

Proposition 5a: There is a positive association between guanxi and performance in China, even though each guanxi-based business variable has a different influence on each performance indicator.

Proposition 5b: Relationships with the Chinese government have a weaker impact on performance than ties with the business community.

\subsection{Local partner attributes}

Drawing mainly on a strategic management perspective, several studies have observed the influence of the length of past collaboration with local partners and the degree to which their product and the product of the IJV are related. On the one hand, a longer relationship between 
partners positively affects performance satisfaction (Lin and Germain 1998), risk reduction and export growth (Luo 1997b, 1997c). On the other hand, the relatedness of IJV product with that of the local partner is positively associated with performance satisfaction (Luo 2002b), ROI, local sales and export growth (Luo 1997b).

We also find other local partner attributes that have a positive influence on certain performance measures for IJVs in China, although in this case there is less empirical evidence (Luo 1997b, 1997c): greater international experience of local partners, a larger market share, greater industry experience, greater absorptive capacity, larger size and whether they are a Chinese state-owned enterprise (SOE).

In view of the greater or lesser empirical support obtained by these local partner attributes, we formulate the following proposition:

Proposition 6: A longer past collaboration with the local partner and greater product relatedness between the local partner and the IJV affect positively the performance of IJVs in China.

\subsection{Experience and knowledge of foreign companies}

The dominant conceptual framework in the papers covering these topics was organisational learning/knowledge management theory. Many studies prove specific experience in China to be a performance driver. Foreign companies in China obtain greater performance when they are active in gaining local knowledge (Han 2002). Knowledge of the market and marketing practices in China and environmental familiarity are positively related with performance (Luo 1999a).

Several studies have found that the intensity of local market experience (number of years operating in China) contributes to improved performance (Abramson and Ai 1999; Carlsson, 
Nordegren, and Sjöholm 2005; Luo 1999b; Luo and Peng 1999). Moreover, Luo (1999b) verified that although this positive effect diminished with cultural distance, time-based experience favours the positive impact of other performance variables (such as resource contribution, market commitment, or innovativeness).

The diversity of experience on the Chinese market (variety of products, breadth of wholesale markets distributed, breadth of retail markets served and diversity of buyers) is also positively related with performance (Luo and Peng 1999). Moreover, while the positive effect of experience intensity on performance diminishes over time, the impact of the diversity of experience remains unchanged.

The results regarding the influence of the company's prior experience in other countries are not quite so conclusive. Abramson and Ai (1999), Carlsson, Nordegren and Sjöholm (2005) and Child and Yan (2003) found that the performance of foreign companies is greater when they have a lot of prior experience in other international markets, not just in countries culturally close to China, but also outside Greater China. However, Han (2002) found that international experience in FDI in other countries does not affect performance in China and even that companies with limited international experience obtain greater performance.

All the above leads us to the distinction between the two types of relevant experience in international business: general international experience, which is gained from operating in the international environment without reference to any specific country; and country-specific experience, obtained through operation in a particular country. Concerning the former kind of experience, if the firm has already been involved in FDIs in several countries, it will have accumulated some capabilities and know how that may be useful. However, they may not be always so relevant for succeeding in China, where cultural distance can make this experience too 
general. In other words, performance in China may be less conditioned by the general international experience acquired by a firm in other countries, than by the specific experience regarding China. Consequently, we propose:

Proposition 7a: Specific experience in China, particularly experience derived from having operated in the country for a longer time, contributes to improved performance.

Proposition 7b: Although prior experience in other countries may provide the firm with some capabilities, cultural distance can make this kind of experience too general for succeeding in China.

\subsection{Strategy and attributes of foreign companies}

Resource dependence theory, the resource-based view, organizational learning and the environment-strategy-performance model have been the mainstream theoretical perspectives in this case. Resource commitment by the foreign investor has a positive influence on performance, particularly for market-seeking companies in China (Luo 1998a, 2003). Moreover, performance is higher when there is a high resource commitment to technology transfer (Isobe, Makino, and Montgomery 2000), the better the quality of the resources provided by the foreign company, in terms of capital investment, new facilities and operational inputs (Child and Yan 2003), and when a high proportion of value chain activities are transferred to China (Abramson and Ai 1999).

The degree to which the products of the IJV and the foreign company's products are related is also positively associated with performance satisfaction. Moreover, subsidiaries pursuing a related diversification strategy where the foreign partner holds a majority equity share obtain greater performance than those with non-related diversification where the foreign partner holds a minority or equal interest or full ownership (Zhao and Luo 2002). 
Regarding business strategy, several studies show that the analyser strategy (a hybrid between the proactive and the defensive strategy, where the company defends existing markets through efficiency-oriented strategy while cautiously penetrating new markets through intensified product/market innovation) leads to a superior performance, in response to the changing environment in China (Luo and Park 2001; Luo and Tan 1998; Luo, Tan, and O'Connor 2001; Tan 2002). Moreover, product quality and low prices as business strategy variables affect performance positively (Luo 1995). The classic trade-off between standardisation and local adaptation has also been studied. While Han (2002) found that foreign companies that employed manufacturing processes similar to those used in their country of origin obtained higher performance in China, Luo (2003) found that the level of local responsiveness has a positive influence on the performance of market-seeking subsidiaries in China.

Relations between the parent company and the Chinese subsidiary can also affect performance. Although a favourable institutional and business environment has a positive influence, Child, Chung and Davies (2003) found that performance can be improved through strategic managerial actions, such as leveraging local resources by developing trust between parent and subsidiary, and maintaining close control and integration with the parent. However, Luo (2003) found that parent firm's control flexibility has a positive influence on subsidiary performance.

With regard to sourcing strategies, in circumstances with low levels of product innovativeness and technological uncertainty, the use of strategic alliance-based sourcing in China has a positive effect on performance (Murray, Kotabe, and Zhou 2005). Nevertheless, 
each sourcing strategy has a different influence on production costs or the building of new technology capabilities (Kotabe and Zhao 2002).

Other strategies analysed have to do with the natural environment. Chan (2005) found that foreign companies that adopt environmental strategies achieve higher environmental and financial performance; however, the study does not confirm that improvements in environmental performance relate to improvements in financial performance.

Other studies dealt with the influence of several firm-specific factors. Thus, the technological and organisational capabilities of the foreign company (Luo 1999a), its efficiency and greater size (Pan, Li, and Tse 1999) positively affect performance, although their influence depends on the measure used.

Finally, Luo (1998a) analysed the differences between foreign investors by country of origin. Some strategic traits (such as market breadth, resource commitment or promotion expenditure) are critically favourable to performance, regardless of country of origin. However, establishing long-term objectives and R\&D intensity contribute to the performance of investors from developed countries, while a proactive attitude favours the performance of investors from emerging markets.

In accordance with the greater or lesser empirical support obtained by the different strategic attributes of foreign companies, we make the following propositions:

Proposition 8a: Resource commitment by foreign investors, a greater product relatedness between the foreign firm and the Chinese subsidiary and following an analyser strategy positively influence performance in China. 
Proposition 8b: The relationship between the parent company and the Chinese subsidiary affects performance, although both close control and greater flexibility may have a positive influence.

Proposition 8c: Certain strategic attributes of foreign investors that have a positive effect on performance in China depend on the level of development of their country of origin.

\subsection{Entry decisions and location in China}

Many papers used a transaction cost approach or a resource-based view to analyse the influence of entry and location decisions. One of the most researched topics in this category has been entry timing. Some studies show that early entrants obtain higher performance than late followers, in terms of market share and return on assets (ROA) (Pan et al. 1999), return on sales (ROS) (Pan and Chi 1999) and perceived performance (Isobe et al. 2000). Nevertheless, the results obtained in other studies do not make it possible to ensure that early entry into China always leads to better performance. Thus, Luo (1998b) found that during the initial period of expansion in China, early entrants outperform late movers in terms of local sales growth and asset turnover, whereas late movers are superior to early entrants with regard to risk reduction and ROI. Li, Lam, Karakowsky and Qian (2003) found that in an industry where technology develops rapidly (such as telecommunications equipment), first-mover strategy may not lead to competitive advantages if the strategy only means entering the market earlier; followers may be able to outperform first-movers by adopting more advanced technology.

Another factor analysed by researchers is entry mode. Abramson and Ai (1999) could not confirm that FDI in China (including either WOS or IJV) leads to greater performance than other entry strategies not involving investments. However, Chen and Hu (2002) showed that foreign investment projects whose modes are selected according to the prescription of the transaction 
cost theory perform better, particularly those that use high control entry modes under the following circumstances: transfer of products and/or processes with a high proprietary content; transfer of marketing skills, brand names and highly differentiated products; entry into Chinese regions and industrial sectors with high potential; great cultural distance with regard to the country of origin; and investment in low capital-intensive projects with long length of stipulated duration.

Several studies have compared performance differences between specific entry modes. WOSs and equity joint ventures (EJVs) obtain a greater market share than contractual joint ventures (CJVs), EJVs obtain greater ROA than CJVs, and there are no differences in ROA between WOSs and CJVs (Pan et al. 1999). EJVs perform better than WOSs in terms of ROS, ROA and assets (Xu, Pan, Wu, and Yim 2006). EJVs obtain greater ROS than WOSs or cooperation agreements (Pan and Chi 1999). In short, and although several performance approaches have been used, these results point to the superiority of EJVs over other entry modes.

Lastly, the influence of the location in China has also been studied. The productivity of foreign firms (output per employee) is affected positively by the following location factors in the region (Li 2004): high development of infrastructures, favourable access to inputs, high concentration of foreign firms and high levels of privatisation. Moreover, foreign companies located in Beijing, Shanghai, and Tianjin and those located in open coastal cities obtained greater ROS than those located in Special Economic Zones (Pan and Chi 1999).

Consequently, we may establish the following propositions:

Proposition 9a: Early entry into China does not always lead to greater performance.

Proposition 9b: Entry modes into China involving a higher level of ownership and control do not always lead to improved performance. 
Proposition 9c: Location advantages in certain regions of China favour performance.

\subsection{Human resource (HR) management practices}

Papers examining the link between HR management practices and performance have used different approaches, such as organizational learning/knowledge management or general systems theories. The evidence regarding the influence of choosing native or expatriate personnel in China is not conclusive. Indeed, local staff and expatriates represent two complementary firm resources that are critical to the success of the local subsidiary (Lam and Yeung, 2009).

Han (2002) found that foreign companies obtain greater performance when they hire more local than expatriate employees. However, Abramson and Ai (1999) could not confirm that acquiring local knowledge through hiring local Chinese managers led to greater performance. Chung (2004) even observed that hiring a Chinese immigrant at headquarters to assist marketing operations in China is a means of overcoming cultural barriers but does not influence performance.

There are some possible reasons for this lack of conclusive findings. First, compared to capital-intensive technologies, labour-intensive technologies may not be in great need of expatriates who are usually technicians and engineers (Han 2002). Second, the hiring of local Chinese managers or employees may not be the best indicator of gains in local market knowledge. Joint venture partners or local consultants may provide this market knowledge instead (Abramson and Ai 1999). Moreover, local employees may not interface well with Western expatriates due to different approaches to interaction and conflict resolution (Abramson and Ai 1999). Finally, the relationship between performance and employee choice cannot stand alone and other factors such as firm characteristics should also be considered (Chung 2004). 
The implementation of retention-oriented management practices (including in-company welfare and long-term commitment practices) have a positive impact on the performance of human resources (in terms of reducing employee turnover and absenteeism), while team-based problem solving practices have a positive influence on financial performance (Takeuchi, Wakabayashi, and Chen 2003). Regarding retention-oriented management practices, they are typically used as a means to promote employees`organizational commitment and work attitudes. It is possible that these practices have a direct positive impact on the behavioural aspect of firm performance, thus reducing worker turnover and absenteeism. Meanwhile, team-based problem solving practices constitute the core of organizational learning and help yield valuable returns to a firm.

HR problems have a different impact on performance (Gong, Shenkar, Luo, and Nyaw 2005). Internal HR problems in the IJV (e.g. compensation gaps between different national employee groups, or lack of training) are negatively related with performance. These internal problems degrade the human capital pool, decrease workforce cohesion and motivation, and may create perceptions of inequity, leading to dissatisfaction and friction among employee groups. On the other hand, HR problems linked to the interaction between the IJV and the parent company (e.g. blocked promotion of host country nationals in local parent headquarters or difficulties of re-entry of expatriates to foreign parent headquarters) are positively related with performance. This friction associated with the interface or relational HR issues serves to solidify the venture's borders, establishes its independence, and consolidates its initial human capital pool, being indicative of HRs that are vested in the venture subsystem.

However, interaction problems have an indirect negative impact on performance through internal HR problems. Relational parent-IJV tensions may adversely affect the performance of 
the within-IJV HR subsystem, hampering continuous resource flow from the parent into the IJV. For example, owing to relational HR tension, the parent may disengage from the IJV by investing less in venture employee training and human capital upgrading, leading to lower IJV performance. Thus, the relational HR set may be positively related to the within-IJV HR set, which in turn is negatively related to IJV performance.

This leads us to formulate the following propositions:

Proposition 10a: Hiring local employees instead of expatriates does not necessarily lead to greater performance in China, other factors affecting this relationship, such as industry and firm characteristics or the market knowledge provided by a local parent or consultant.

Proposition 10b: Retention-oriented management practices in China improve the performance of human resources, while team problem-solving practices improve financial performance

Proposition 10c: Internal HR problems in the IJV affect performance negatively, while $H R$ problems linked to the interaction with the parent company have an indirect negative effect through internal HR problems.

\subsection{Industry structure factors}

Industrial organisation has been the dominant conceptual framework used here. Several structural industry factors affect performance, positively or negatively depending on the measure used. Thus, industry sales growth and industry profitability have a positive effect on ROA (Luo 1995), ROI and domestic sales growth (Luo 1995; Luo and Tan 1997), but a negative effect on export growth (Luo 1995; Luo and Tan 1997). Industry profitability also has a negative impact on risk reduction (Luo and Tan 1997). Industry asset intensity has a positive impact on ROI, but 
a negative impact on exports and risk reduction (Luo and Tan 1997). Finally, industry uncertainty increases the operational risk of the foreign company (Luo and Tan 1997).

The number of companies in the industry is another factor which has not thrown up conclusive results. Luo and Tan (1997) observe that the growth in the number of companies in the industry is positively associated with ROI and domestic sales growth. However, Pan et al. (1999) found that sector concentration has a positive impact on the market share of foreign companies in China, but a negative impact on their ROA.

Consequently, our proposition is as follows:

Proposition 11: Industry structure factors may have positive or negative effects on performance in China, depending on the measure used.

\subsection{Differences in the performance criteria used by IJV partners}

In the final sub-section of results we have included two papers that, using a multipleparty approach, analysed the differences between partners with regard to the criteria used to evaluate the performance of IJVs in China. Thus, Osland and Cavusgil (1998) find that US parent company managers are more likely to use ROI or internal rate of return, while Chinese parent company managers focus on dividends and consider technology transfer and foreign exchange earnings as important performance criteria. Mohr (2006) reports that the use of, and the importance attributed to the performance indicators 'acquisition of technology and knowledge' and 'stability' differ between Chinese and German firms involved in IJVs, being more relevant to the Chinese side.

Accordingly, we make the following proposition: 
Proposition 12: There are differences in the performance evaluation criteria used by Chinese and Western partners in IJVs, the Chinese side showing greater interest in the acquisition of knowledge and technology.

\section{Conclusions}

Ever since the open-door policy came into effect in China, the key success factors for doing business in the country have become one of the subjects that have aroused greatest interest in international business and management research. Either as a specific subject or complementarily, several studies have researched performance drivers of foreign companies in China.

The main contribution of this work has been to systematise the results obtained in former empirical studies in order to identify which factors are more decisive to greater performance. Although other studies have reviewed the literature in the Chinese context, none had specifically tackled this important topic through a comprehensive review.

Nevertheless, we are aware of the limitations of this review. First, the limitation inherent to any literature review: the selection of journals. Although all are leading and high impact international journals, studies analysing this matter may have appeared in other publications. In addition, the papers reviewed here are heterogeneous with regard to the performance measures used. Although we have tried to make reference to this fact in presenting our main findings, it needs to be kept in mind when interpreting the results. Finally, although many papers covered by our review dealt only with IJVs in China, some of them also included WOSs in their samples. We tried to separate the analysis of the two ownership structures by analysing papers dealing only with IJVs in the same sub-section. However, the interpretation of the findings reported in 
the rest of sub-sections must be made with caution, since the success factors for IJVs and WOSs may be different.

In spite of this, our review has allowed us to identify an accumulated base of knowledge sufficient to reach certain interesting conclusions. First, the empirical evidence allows us to conclude that certain factors may be more determinant in favouring performance in China. Thus, cooperation between partners, a contractual design adapted to local conditions, establishing guanxi-based relationships, longer past collaboration with the Chinese partner, experience derived from the number of years operating in China, the resource commitment by the foreign partner, the product relatedness between the subsidiary and the parent companies, following an analyser strategy, location advantages in specific regions, and certain human resources practices (such as retention-oriented management practices or team problem-solving practices) are all factors that have a positive influence on the performance of foreign companies in China (Fig. 1). Insert figure 1 about here

Moreover, our review has also allowed us to identify certain factors whose influence on performance has not received conclusive empirical support, such as the level of control by the foreign partner, cultural differences with the Chinese partner, entry timing, entry mode, the hiring of local employees or industry structure factors.

Consequently, 30 years after the open-door policy came into effect in China, there are still issues needing further research. In our opinion, two subjects demand additional attention: cultural distance between China and the country of origin of the foreign company, and the choice between expatriate and local employees. As this review has pointed out, so far empirical research has not reached a consensus on how cultural distance or the type of employee contribute to 
improving the performance of foreign companies in China. This opens two promising avenues of future research.

\section{References}

Abramson, N.R., and J.X. Ai (1999). Canadian companies doing business in China: Key success factors. Management International Review 39 (1), pp. 7-35.

Acedo, F.J., and J.C. Casillas (2005). Current paradigms in the international management field: An author cocitation analysis. International Business Review 14 (5), pp. 619-639.

Bhasin, B.B. (2007). Succeeding in China: Cultural adjustments for Indian businesses. Cross Cultural Management: An International Journal 14 (1), pp. 43-53.

Carlsson, J., A. Nordegren, and F. Sjöholm (2005). International experience and the performance of Scandinavian firms in China. International Business Review 14 (1), pp. 21-40.

Chan, K.C., H.G. Fung, and W.K. Leung (2006). International business research: Trends and school rankings. International Business Review 15 (4), pp. 317-338.

Chan, R.Y.K. (2005). Does the natural-resource-based view of the firm apply in an emerging economy? A survey of foreign invested enterprises in China. Journal of Management Studies 42 (3), pp. 625-672.

Chen, H., and M.Y. Hu (2002). An analysis of determinants of entry mode and its impact on performance. International Business Review 11 (2), pp. 193-210.

Child, J., and Y. Yan (2003). Predicting the performance of international joint ventures: An investigation in China. Journal of Management Studies 40 (2), pp. 283-320.

Child, J., L. Chung, and H. Davies (2003). The performance of cross-border units in China: A test of natural selection, strategic choice and contingency theories. Journal of International Business Studies 34 (3), pp. 242-254.

Chung, H.F.L. (2004). An empirical investigation of immigrant effects: The experience of firms operating in the emerging markets. International Business Review 13 (6), pp. 705-728.

Dubois, F.L., and D. Reeb (2000). Ranking the international business journals. Journal of International Business Studies 31 (4), pp. 689-704.

Gong, Y., O. Shenkar, Y. Luo, and M.K. Nyaw (2005). Human resources and international joint venture performance: A system perspective. Journal of International Business Studies 36 (5), pp. 505-518.

Grow, R.F. (1986). Japanese and American firms in China: Lessons of a new market. Columbia Journal of World Business 21 (1), pp. 49-56.

Han, C.M. (2002). Korea's direct investments in China: Technology, experience, and ownership factors in performance. Asia Pacific Journal of Management 19 (1), pp. 109-126.

Hofstede, G. (1980). Culture's Consequences. International Differences in Work-Related Values. Newbury Park, California: Sage Publications. 
Isobe, T., S. Makino, and D.B. Montgomery (2000). Resource commitment, entry timing, and market performance of foreign direct investments in emerging economies: The case of Japanese international joint ventures in China. Academy of Management Journal 43 (3), pp. 468-484.

Kotabe, M., and H. Zhao (2002). A taxonomy of sourcing strategic types for MNCs operating in China. Asia Pacific Journal of Management 19 (1), pp. 11-27.

Kumar, V., and S.K. Kundu (2004). Ranking the international business schools: Faculty publication as the measure. Management International Review 44 (2), pp. 213-228.

Lam, S.S.K., and J.C.K. Yeung (2009). Staff localization and environmental uncertainty on firm performance in China. Asia Pacific Journal of Management (forthcoming).

Li, J., L. Karakowsky, and K. Lam (2002). East meets East and East meets West: The case of Sino-Japanese and Sino-West joint ventures in China. Journal of Management Studies 39 (6), pp. 841-863.

Li, J., K. Lam, and G. Qian (2001). Does culture affect behavior and performance of firms? The case of joint ventures in China. Journal of International Business Studies 32 (1), pp. 115-131.

Li, J., K.C.K. Lam, L. Karakowsky, and G. Qian (2003). Firm resource and first mover advantages. A case of foreign direct investment (FDI) in China. International Business Review 12 (5), pp. 625-645.

Li, J.J. (2005). The formation of managerial networks of foreign firms in China: The effects of strategic orientations. Asia Pacific Journal of Management 22 (4), pp. 423- 443.

Li, J.J., K.Z. Zhou, and A.T. Shao (2009). Competitive position, managerial ties, and profitability of foreign firms in China: An interactive perspective. Journal of International Business Studies 40 (2), pp. 339-352.

Li, J.T., and A.S. Tsui (2002). A citation analysis of management and organization research in the Chinese context: 1984-1999. Asia Pacific Journal of Management 19 (1), pp. 87-107.

Li, S. (2004). Location and performance of foreign firms in China. Management International Review 44 (2), pp. 151-169.

Lin, X., and R. Germain (1998). Sustaining satisfactory joint venture relationships: The role of conflict resolution strategy. Journal of International Business Studies 29 (1), pp. 179-196.

Lohrke, F.T., and G.D. Bruton (1997). Contributions and gaps in international strategic management literature. Journal of International Management 3 (1), pp. 25-57.

Lu, J.W. (2003). The evolving contributions in international strategic management research. Journal of International Management 9 (2), pp. 193-213.

Luo, Y. (1995). Business strategy, market structure, and performance of international joint ventures: The case of joint ventures in China. Management International Review 35 (3), pp. 242-264.

Luo, Y. (1997a). Guanxi and performance of foreign-invested enterprises in China: An empirical inquiry. Management International Review 37 (1), pp. 51-70.

Luo, Y. (1997b). Partner selection and venturing success: The case of joint ventures with firms in the People's Republic of China. Organization Science 8 (6), pp. 648-662.

Luo, Y. (1997c). Performance effects of local partner attributes: An empirical analysis of strategic alliances in an emerging economy. Journal of International Management 3 (2), pp. 119-152. 
Luo, Y. (1998a). Strategic traits of foreign direct investment in China: A country of origin perspective. Management International Review 38 (2), pp. 109-132.

Luo, Y. (1998b). Timing of investment and international expansion performance in China. Journal of International Business Studies 29 (2), pp. 391-408.

Luo, Y. (1999a). Dimensions of knowledge: Comparing Asian and Western MNEs in China. Asia Pacific Journal of Management 16 (1), pp. 75-93.

Luo, Y. (1999b). Time-based experience and international expansion: The case of an emerging economy. Journal of Management Studies 36 (4), pp. 505-534.

Luo, Y. (2001). Toward a cooperative view of MNC-host government relations: Building blocks and performance implications. Journal of International Business Studies 32 (3), pp. 401-419.

Luo, Y. (2002a). Contract, cooperation, and performance in international joint ventures. Strategic Management Journal 23 (10), pp. 903-919.

Luo, Y. (2002b). Product diversification in international joint ventures: Performance implications in an emerging market. Strategic Management Journal 23 (1), pp. 1-20.

Luo, Y. (2002c). Stimulating exchange in international joint ventures: An attachment-based view. Journal of International Business Studies 33 (1), pp. 169-181.

Luo, Y. (2003). Market-seeking MNEs in an emerging market: How parent-subsidiary links shape overseas success. Journal of International Business Studies 34 (3), pp. 290-309.

Luo, Y. (2005). How important are shared perceptions of procedural justice in cooperative alliances? Academy of Management Journal 48 (4), pp. 695-709.

Luo, Y., and M. Chen (1996). Managerial implications of guanxi-based business strategies. Journal of International Management 2 (4), pp. 293-316.

Luo, Y., and M. Chen (1997). Does guanxi influence firm performance? Asia Pacific Journal of Management 14 (1), pp. 1-16.

Luo, Y., and S.H. Park (2001). Strategic alignment and performance of market-seeking MNCs in China. Strategic Management Journal 22 (2), pp. 141-155.

Luo, Y., and S.H. Park (2004). Multiparty cooperation and performance in international equity joint ventures. Journal of International Business Studies 35 (2), pp. 142-160.

Luo, Y., and M.W. Peng (1999). Learning to compete in a transition economy: Experience, environment, and performance. Journal of International Business Studies 30 (2), pp. 269-296.

Luo, Y., and O. Shenkar (2002). An empirical inquiry of negotiation effects in cross-cultural joint ventures. Journal of International Management 8 (2), pp. 141-162.

Luo, Y., and J. Tan (1997). How much does industry structure impact foreign direct investment in China? International Business Review 6 (4), pp. 337-359.

Luo, Y., and J. Tan (1998). A comparison of multinational and domestic firms in an emerging market: A strategic choice perspective. Journal of International Management 4 (1), pp. 21-40. 
Luo, Y., and J. Tan (2003). Structuring international joint ventures: How should contractual design be aligned with environmental conditions? Management International Review 43 (2), pp. 185-211.

Luo, Y., O. Shenkar, and M.K. Nyaw (2001). A dual parent perspective on control and performance in international joint ventures: Lessons from a developing economy. Journal of International Business Studies 32 (1), pp. 4158.

Luo, Y., O. Shenkar, and M.K. Nyaw (2002). Mitigating liabilities of foreignness: Defensive versus offensive approaches. Journal of International Management 8 (3), pp. 283-300.

Luo, Y., J.J. Tan, and N.G. O'Connor (2001). Strategic response to a volatile environment: The case of cross-cultural cooperative ventures. Asia Pacific Journal of Management 18 (1), pp. 7-25.

Mohr, A.T. (2006). A multiple constituency approach to IJV performance measurement. Journal of World Business 41 (3), pp. 247-260.

Morrison, A.J., and A.C. Inkpen (1991). An analysis of significant contributions to the international business literature. Journal of International Business Studies 22 (1), pp. 143-153.

Murray, J.Y., M. Kotabe, and J.N. Zhou (2005). Strategic alliance-based sourcing and market performance: Evidence from foreign firms operating in China. Journal of International Business Studies 36 (2), pp. 187208.

Newburry, W., Y. Zeira, and O. Yeheskel (2003). Autonomy and effectiveness of equity international joint ventures (IJVs) in China. International Business Review 12 (4), pp. 395-419.

Nippa, M., S. Beechler, and A. Klossek (2007). Success factors for managing international joint ventures: A review and an integrative framework. Management and Organization Review 3 (2), pp. 277-310.

Osland, G.E., and G.T. Cavusgil (1998). The use of multiple-party perspectives in international joint venture research. Management International Review 38 (3), pp. 191-202.

Pan, Y., and P.S.K. Chi (1999). Financial performance and survival of multinational corporations in China. Strategic Management Journal 20 (4), pp. 359-374.

Pan, Y., S. Li, and D.K. Tse (1999). The impact of order and mode of market entry on profitability and market share. Journal of International Business Studies 30 (1), pp. 81-104.

Peng, M.W., Y. Lu, O. Shenkar, and D.Y.L. Wang (2001). Treasures in the China house. A review of management and organizational research on Greater China. Journal of Business Research 52 (2), pp. 95-110.

Peng, M.W., and J.Q. Zhou (2006). Most cited articles and authors in global strategy research. Journal of International Management, 12 (4), pp. 490-508.

Quer, D., E. Claver, and L. Rienda (2007). Business and management in China: A review of empirical research in leading international journals. Asia Pacific Journal of Management 24 (3), pp. 359-384.

Roy, A., P.G.P. Walters, and S.T.K. Luk (2001). Chinese puzzles and paradoxes: Conducting business research in China. Journal of Business Research 52 (2), pp. 203-210.

Sanyal, R.N., and T. Guvenli (2000). Relations between multinational firms and host governments: The experience of American-owned firms in China. International Business Review 9 (1), pp. 119-134. 
Shenkar, O. (1994). The People's Republic of China. Raising the bamboo screen through international management research. International Studies of Management and Organization 24 (1-2), pp. 9-34.

Shenkar, O., and M.A. Von Glinow (1994). Paradoxes of organization theory and research: Using the case of China to illustrate national contingency. Management Science 40 (1), pp. 56-71.

Takeuchi, N., M. Wakabayashi, and Z. Chen (2003). The strategic HRM configuration for competitive advantage: Evidence from Japanese firms in China and Taiwan. Asia Pacific Journal of Management 20 (4), pp. 447480 .

Tan, J. (2002). Impact of ownership type on environment-strategy linkage and performance: Evidence from a transitional economy. Journal of Management Studies 39 (3), pp. 333-354.

Tsui, A.S., C.B. Schoonhoven, M.W. Meyer, C.M. Lau, and G.T. Milkovich (2004). Organization and management in the midst of societal transformation: The People's Republic of China. Organization Science 15 (2), pp. 133-144.

UNCTAD (2008). World Investment Report 2008. Transnational Corporations and the Infrastructure Challenge. New York and Geneva: United Nations.

Wang, P., C.H. Wee, and P.H. Koh (1998). Control mechanisms, key personnel appointment, control and performance of Sino-Singaporean joint ventures. International Business Review 7 (4), pp. 351-375.

Wang, P., C.H. Wee, and P.H. Koh (1999). Establishing a successful Sino-foreign equity joint venture: The Singapore experience. Journal of World Business 34 (3), pp. 287-305.

Werner, S. (2002). Recent developments in international management research: A review of 20 top management journals. Journal of Management 28 (3), pp. 277-305.

Werner, S., and L.E. Brouthers (2002). How international is management? Journal of International Business Studies 33 (3), pp. 583-591.

Xu, D., Y. Pan, C. Wu, and B. Yim (2006). Performance of domestic and foreign-invested enterprises in China. Journal of World Business 41 (3), pp. 261-274.

Xu, S., G. Yalcinkaya, and S.H. Seggie (2008). Prolific authors and institutions in leading international business journals. Asia Pacific Journal of Management 25 (2), pp. 189-207.

Yan, A., and J. Duan (2003). Interpartner fit and its performance implications: A four-case study of U.S.-China joint ventures. Asia Pacific Journal of Management 20 (4), pp. 541-564.

Yan, A., and B. Gray (1994). Bargaining power, management control, and performance in United States-China joint ventures: A comparative case study. Academy of Management Journal 37 (6), pp. 1478-1517.

Yan, A., and B. Gray (2001). Antecedents and effects of parent control in international joint ventures. Journal of Management Studies 38 (3), pp. 393-416.

Yan, Y., and J. Child (2004). Investors' resources and management participation in international joint ventures: A control perspective. Asia Pacific Journal of Management 21 (3), pp. 287-304.

Yang, Z., X. Wang, and C. Su (2006). A review of research methodologies in international business. International Business Review 15 (6), pp. 601-617. 
Zhang, Y., and H. Li (2001). The control design and performance in international joint ventures: A dynamic evolution perspective. International Business Review 10 (3), pp. 341-362.

Zhao, H., and Y. Luo (2002). Product diversification, ownership structure, and subsidiary performance in China's dynamic market. Management International Review 42 (1), pp. 27-48.

Zhou, K.Z., and C.B. Li (2007). How does strategic orientation matter in Chinese firms? Asia Pacific Journal of Management 24 (4), pp. 447-466. 


\section{Figures}

\section{Figure 1}

Key performance drivers of foreign firms in China

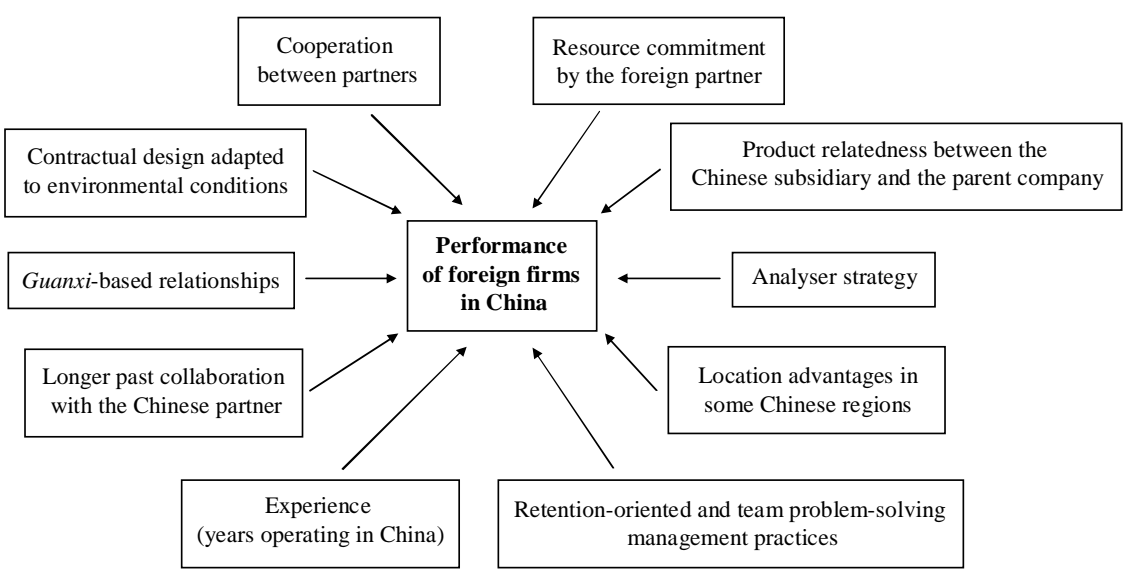




\section{Notes}

\footnotetext{
${ }^{1}$ Nippa et al. (2007) report evidence of some consistent findings: a strong strategic commitment by foreign and local parent organizations, trust and cooperative behaviour as well as implementing adequate control mechanisms are of great relevance for the success of both China and non-China IJVs. Regarding inconsistent findings, they report that while IJV 'size' has a mixed impact on performance in non-China studies, it shows almost no correlation with success of Sino-foreign IJVs. In addition, surveys in China prove, with the exception of 'cultural distance', that more 'fit' variables between foreign and local parent organizations predict IJV performance than do non-China studies.

${ }^{2}$ While Westerners tend to expect resolution of disputes through legal action, the Chinese have less experience in any legal system (Bhasin 2007).

${ }^{3}$ Regarding this point, some European culture studies show that what is similar, for instance German and Dutch or Belgium and The Netherlands, is often more difficult than what is more remote: The Netherlands-Russia or FinlandItaly.
} 